\title{
Redução da severidade da podridão-amarga de maçã em pós-colheita pela imersão de frutos em quitosana
}

\author{
Ricardo Barbosa Felipini(1) e Robson Marcelo Di Piero(1) \\ 1)Universidade Federal de Santa Catarina, Centro de Ciências Agrárias, Departamento de Fitotecnia, Laboratório de Fitopatologia, \\ CEP 88034-001, Florianópolis, SC, Brasil. E-mail: ricardo_felipini@yahoo.com.br, robson@cca.ufsc.br
}

Resumo - O objetivo deste trabalho foi avaliar a aplicação de quitosana no controle da podridão-amarga da maçã em pós-colheita e seus efeitos sobre Colletotrichum acutatum e a atividade da peroxidase nos frutos. Frutos previamente infectados com o patógeno foram imersos em suspensões de quitosana com diferentes concentrações e pHs. Para estudar possíveis mecanismos de ação envolvidos no controle da doença, foram realizados testes in vitro, para avaliar o efeito da quitosana sobre a germinação de conídios de C. acutatum e sobre o crescimento micelial. Foi avaliada a capacidade da quitosana de induzir a síntese de enzimas relacionadas à defesa da planta (peroxidases), por meio de ensaio espectrofotométrico. Houve efeito de doses e de pH da quitosana sobre a redução da severidade da podridão-amarga em maçã. A suspensão de quitosana a $10 \mathrm{~g} \mathrm{~L}^{-1}$ e $\mathrm{pH} 4$ foi a mais apropriada tecnicamente para o controle da doença, pois reduziu a severidade em $26 \%$. O polissacarídeo não elevou a atividade de peroxidases nos frutos, mas reduziu a germinação de conídios e o crescimento micelial do patógeno. A quitosana aplicada em pós-colheita é uma medida alternativa aos fungicidas para o manejo da podridão-amarga.

Termos para indexação: Colletotrichum acutatum, antibiose, controle alternativo, indução de resistência.

\section{Reduction of the severity of apple bitter rot by fruit immersion in chitosan}

\begin{abstract}
The objective of this work was to evaluate the aplication of chitosan on the control of apple bitter rot in postharvest conditions and its effects on Colletotrichum acutatum and fruit peroxidase activity. Apple fruit previously infected with the pathogen were immersed in chitosan suspensions with different concentrations and pHs. To study some possible action mechanisms, in vitro tests were carried out to evaluate the effect of chitosan on spore germination and mycelial growth of $C$. acutatum. The capacity of chitosan to induce the synthesis of defense enzymes (peroxidases) was evaluated in fruits by spectrofotometric assay. Different doses and $\mathrm{pH}$ of chitosan were found to be effective in the reduction of the disease severity. Chitosan at $10 \mathrm{~g} \mathrm{~L}^{-1}(\mathrm{pH}$ 4) had the most technical viability for the control of the disease and reduced the severity in $26 \%$. Considering the action mechanisms, chitosan did not increase peroxidase activity in the fruits; however, it reduced both spore germination and mycelial growth of the pathogen. Chitosan applied at postharvest is an alternative to reduce bitter rot severity.
\end{abstract}

Index terms: Colletotrichum acutatum, antibiosis, natural control, resistance induction.

\section{Introdução}

A podridão-amarga da macieira, causada pelo fungo Colletotrichum acutatum (Penz.) Sacc.) pode resultar em significativas perdas de produção (Denardi et al., 2003). Os conídios são dispersos a partir dos acérvulos, principalmente pela água, e germinam ao se depositar na planta, em ambiente favorável, podendo emitir apressórios e penetrar diretamente ou por meio das lenticelas e ferimentos. A infecção pode ocorrer logo após a floração, no início do desenvolvimento do fruto, que se torna mais suscetível à medida que amadurece. Os sintomas podem aparecer ainda no campo, de acordo com o ambiente, ou se manifestar durante o período de armazenamento. Inicialmente, ocorrem pequenas lesões pardas a marrom-claras que, ao atingir cerca de $2 \mathrm{~cm}$ de diâmetro, ficam deprimidas. Em condições de alta umidade, torna-se visível a presença de mucilagem de coloração rósea no centro das lesões, onde se encontram os conídios do fitopatógeno (Bleicher, 2002).

O controle da doença é realizado principalmente pela aplicação de fungicidas protetores (Boneti et al., 2002). Ultimamente, em razão da maior procura dos consumidores por produtos livres de resíduos de agrotóxicos e pela seleção de populações resistentes de fitopatógenos aos fungicidas convencionais, 
tem-se buscado o desenvolvimento de outras formas de controle. Entre os produtos com potencial de uso agrícola, encontra-se o polissacarídeo quitosana, obtido a partir da desacetilação da quitina, que é o maior constituinte de exoesqueletos de crustáceos e de outros animais marinhos (Goosen, 1997). Trata-se de um produto de baixa toxidez, capaz de formar géis e com atividade antimicrobiana. Esses são atributos que fazem com que a quitosana seja estudada para aplicação em pós-colheita de frutos, tanto in natura, quanto minimamente processados (Assis \& Leoni, 2003).

A quitosana pode retardar o crescimento micelial, diminuir a germinação de conídios e causar alterações morfológicas no tubo germinativo de algumas espécies de fitopatógenos (El Ghaouth et al., 1994; Liu et al., 2007). Pode, também, diminuir a severidade de doenças em pós-colheita de mamão, tomate, pepino, maçã e uva, atuando diretamente sobre o fitopatógeno e induzindo resistência nos frutos (De Capdeville et al.; 2002; Cia, 2005; Bautista-Baños et al., 2006).

$\mathrm{O} \mathrm{pH}$ está entre os principais fatores que influenciam as características da quitosana, pois altera a protonação dos grupamentos amino e a capacidade de solvatação do polissacarídeo. Em pHs mais elevados, as cadeias do biopolímero se aproximam, pela redução na protonação, o que resulta em maior viscosidade. Em pHs mais baixos, em razão da maior protonação nas cadeias, ocorre melhor dissolução da quitosana (Santos et al., 2003).

Com relação à indução de respostas de defesa em plantas, a quitosana atuaria como eliciador ao desencadear mecanismos estruturais de resistência - como a formação de papilas - e mecanismos bioquímicos como a produção de fitoalexinas e proteínas relacionadas à patogênese (Cavalcanti et al., 2005). Em frutos de maçã, a capacidade da quitosana de induzir resistência foi demonstrada por De Capdeville et al. (2002), quando inocularam Penicillium expansum nos frutos tratados previamente com o polissacarídeo.

Normalmente, o possível agente indutor de resistência é aplicado antes da inoculação. Contudo, no atual estudo, buscou-se avaliar a indução da síntese de peroxidases, em maçãs tratadas com quitosana após a inoculação do fitopatógeno, pois, de acordo com a etiologia da doença, os frutos chegam à pós-colheita já infectados, e o patógeno permanece quiescente até obter condições favoráveis ao seu desenvolvimento (Bleicher, 2002).

O objetivo deste trabalho foi avaliar a aplicação de quitosana no controle da podridão-amarga da maçã em pós-colheita e seus efeitos sobre C. acutatum e a atividade da peroxidase nos frutos.

\section{Material e Métodos}

Os experimentos foram realizados no Laboratório de Fitopatologia do Centro de Ciências Agrárias da Universidade Federal de Santa Catarina, Florianópolis, SC.

$\mathrm{O}$ isolado de $C$. acutatum, obtido de frutos sintomáticos colhidos na região de São Joaquim, SC, foi mantido em meio de cultura batata-dextrose-ágar (BDA), sob fotoperíodo de 12 horas e temperatura de $25^{\circ} \mathrm{C}$. Os conídios do patógeno foram suspensos de colônias puras com dez dias de idade, pela adição de água destilada estéril. A concentração de conídios foi determinada com hemacitômetro e ajustada para $10^{5}$ conídios $\mathrm{mL}^{-1}$.

O polissacarídeo quitosana, com $85 \%$ de desacetilação, foi fornecido pela Empresa AD Oceanum Indústria e Comércio Ltda. (Governador Celso Ramos, $\mathrm{SC})$ e apresenta fórmula molecular $\left(\mathrm{C}_{8} \mathrm{H}_{13} \mathrm{NO}_{5}\right) \mathrm{n}$. A suspensão do polissacarídeo foi preparada pela dissolução em $\mathrm{HCl}$ 0,05 N com agitação constante e correção do $\mathrm{pH}$ com NaOH $2 \mathrm{~mol} \mathrm{~L}^{-1}$.

Os frutos de maçã da cultivar Fuji, colhidos na safra 2007/2008, foram cedidos pela Cooperserra, São Joaquim, SC, armazenados a $4^{\circ} \mathrm{C}$ e utilizados dentro de um período de quatro meses. Antes de sua utilização, foram imersos em solução de hipoclorito de sódio $(0,025 \%$ cloro ativo) durante $2 \mathrm{~min}$, lavados em água corrente e secos ao ar, à temperatura ambiente.

No primeiro experimento, os frutos de maçã foram infectados com $20 \mu \mathrm{L}$ de suspensão de conídios $\left(10^{5}\right.$ conídios $\left.\mathrm{mL}^{-1}\right)$ na região equatorial, em faces opostas, por injeção com agulha de $0,25 \mathrm{~mm}$ de diâmetro e $4 \mathrm{~mm}$ de profundidade, e colocados em câmara úmida, no interior de bandejas de plástico $(400 \times 270 \times 133 \mathrm{~mm})$, por 24 horas a $25^{\circ} \mathrm{C}$. Após esse período, as maçãs foram imersas durante $1 \mathrm{~min}$ em suspensão de quitosana de $0,2,5,5,7,5$ ou $10 \mathrm{~g} \mathrm{~L}^{-1}$ com $\mathrm{pH}$ ajustado para 5,6 , e foram mantidas à mesma temperatura, no escuro. A avaliação da severidade da doença foi realizada semanalmente e começou dez 
dias após a inoculação (DAI); o diâmetro das lesões foi medido em sentidos ortogonais, e a área abaixo da curva de progresso da doença (AACPD) foi calculada conforme Shanner \& Finney (1977). O delineamento experimental foi inteiramente casualizado, com quatro repetições. Cada unidade experimental foi composta por uma bandeja com quatro frutos.

No segundo experimento, os frutos foram infectados com $20 \mu \mathrm{L}$ de suspensão de conídios $\left(10^{3}, 10^{4}\right.$ ou $10^{5}$ conídios $\left.\mathrm{mL}^{-1}\right)$ e, após 24 horas em câmara úmida, foram imersos em água destilada ou quitosana $\left(10 \mathrm{~g} \mathrm{~L}^{-1}\right)$ por $1 \mathrm{~min}$. Em um terceiro experimento, os frutos foram infectados com $20 \mu \mathrm{L}$ da suspensão de conídios $\left(10^{5}\right.$ conídios $\left.\mathrm{mL}^{-1}\right)$ e, após permanecerem em câmara úmida por 24 horas, foram imersos por 1 min em água destilada ou em suspensões de quitosana (10 ou $20 \mathrm{~g} \mathrm{~L}^{-1}$ ) associadas a três valores de $\mathrm{pH}(2,4,4$ ou 5,6$)$. Nesses experimentos, a unidade experimental consistiu de uma bandeja com 4 frutos, que foram incubados no escuro, a $25^{\circ} \mathrm{C}$, em delineamento inteiramente ao acaso, com quatro repetições. A avaliação da severidade da doença foi realizada conforme descrito anteriormente.

No experimento de germinação de conídios, foram avaliadas as doses de $0,25,50,75$ e $100 \mu \mathrm{g} \mathrm{mL}^{-1}$ de quitosana, com $\mathrm{pH}$ ajustado para 5,6. Os testes foram realizados em lâminas de microscopia escavadas, onde $20 \mu \mathrm{L}$ de quitosana foram adicionados sobre $20 \mu \mathrm{L}$ da suspensão de conídios $\left(10^{5}\right.$ conídios $\left.\mathrm{mL}^{-1}\right)$ com $2 \%$ de dextrose $(\mathrm{m} / \mathrm{v})$. As lâminas foram dispostas em placas de Petri e incubadas à luz em ambiente com alta umidade relativa, a $25^{\circ} \mathrm{C}$. Após 20 horas, foi avaliada a percentagem de germinação de conídios, tendo-se considerado germinado aquele em que o comprimento do tubo germinativo ultrapassou o comprimento do conídio. O delineamento foi completamente casualizado, com cinco repetições, e cada unidade experimental foi constituída por uma lâmina com $20 \mu \mathrm{L}$ da suspensão.

Para avaliar o efeito sobre o crescimento micelial do fungo, suspensões de quitosana com $\mathrm{pH} 5,6$ foram incorporadas ao meio de cultura BDA, após autoclavagem, nas proporções $0,1,2,3$ ou $4 \mathrm{~g} \mathrm{~L}^{-1}$, e vertidas em placas de Petri. No centro de cada placa foi disposto um disco ( $6 \mathrm{~mm}$ de diâmetro) com micélio do fungo, repicado de uma colônia de dez dias. As placas foram incubadas a $25^{\circ} \mathrm{C}$, em fotoperíodo de 12 horas. $\mathrm{O}$ delineamento experimental foi completamente casualizado, com cinco repetições, com uma placa para cada repetição. $\mathrm{O}$ diâmetro de todas as colônias foi medido quando uma delas atingiu a extremidade da placa.

Em um lote com 50 frutos de maçã avaliou-se a atividade de peroxidases em frutos tratados ou não com quitosana. Cada fruto recebeu $20 \mu \mathrm{L}$ de água destilada na região equatorial, em cinco pontos eqüidistantes, à profundidade de $4 \mathrm{~mm}$, por meio de agulha de $0,25 \mathrm{~mm}$ de diâmetro. Outro lote de 50 frutos foi infectado com suspensão de conídios de C. acutatum $\left(20 \mu \mathrm{L}, 10^{5}\right.$ conídios $\mathrm{mL}^{-1}$ ) na região equatorial, conforme descrito acima. Vinte e quatro horas depois, metade dos frutos de cada lote foi imersa em água destilada, e a outra metade em suspensão de quitosana $\left(10 \mathrm{~g} \mathrm{~L}^{-1}\right)$, por $1 \mathrm{~min}$, no total de 4 tratamentos. Foi realizado, também, um quinto tratamento apenas com imersão de 25 maçãs em água destilada. Os frutos de cada tratamento foram dispostos em cinco bandejas, com cinco frutos em cada uma. Aleatoriamente, nos intervalos de tempo de $0,24,48,72$ e 96 horas após a imersão em água ou quitosana, foi amostrado um fruto de cada bandeja, tendo-se retirado cinco cubos de $5 \mathrm{~mm}$ de diâmetro e $8 \mathrm{~mm}$ de profundidade do local onde foi realizada a injeção com água destilada ou suspensão de conídios. Cada amostra, constituída por cinco cubos oriundos de cinco maçãs diferentes, submetidas a um mesmo tratamento, foi armazenada à temperatura de $-20^{\circ} \mathrm{C}$.

As amostras foram maceradas em nitrogênio líquido, homogeneizadas em $1,5 \mathrm{~mL}$ de tampão fosfato $100 \mathrm{mmol} \mathrm{L}^{-1}(\mathrm{pH}$ 7) e centrifugadas a $20.000 \mathrm{~g}$ por $30 \mathrm{~min}$, a $4^{\circ} \mathrm{C}$. A atividade de peroxidases foi avaliada por espectrofotometria a $470 \mathrm{~nm}$, a partir dos sobrenadantes coletados. A reação consistiu de $0,3 \mathrm{~mL}$ do sobrenadante e $2,7 \mathrm{~mL}$ de tampão fosfato $50 \mathrm{mmol} \mathrm{L}^{-1}$ (pH 6), com guaiacol 0,25\% (v/v) e peróxido de hidrogênio $0,1 \mathrm{~mol} \mathrm{~L}^{-1}$, a $40^{\circ} \mathrm{C}$ (Hammerschmidt et al., 1982). Foram feitas leituras de absorbância a cada $30 \mathrm{~s}$, durante $4 \mathrm{~min}$. Os resultados da atividade de peroxidases foram expressos em unidades de densidade óptica (DO) a $470 \mathrm{~nm} \mathrm{mg}^{-1}$ de proteína por minuto. A determinação de proteínas totais nas amostras foi realizada pelo método de Bradford (1976). Os dados foram analisados em esquema bifatorial $5 \times 5$.

A homogeneidade das variâncias foi verificada pelo teste de Levene a $5 \%$ de probabilidade e, posteriormente, os dados foram submetidos à análise de variância e ao teste $\mathrm{F}$ a $5 \%$ de probabilidade. Nos experimentos com 
fatores quantitativos, realizou-se a análise de regressão linear com o programa estatístico Sisvar 4.3 (Ferreira, 2009), enquanto, nos experimentos qualitativos, as médias dos tratamentos foram comparadas pelo teste de Student-Newman-Keuls (SNK), a 5\% de probabilidade.

\section{Resultados e Discussão}

Aquitosana reduziu a severidade da podridão-amarga em frutos de maçã 'Fuji', imersos na suspensão do polissacarídeo 24 horas depois da inoculação. A redução foi diretamente proporcional à dose de quitosana (Figura 1).

No experimento bifatorial ( $3 \times 2)$, em que os frutos de maçãs foram infectados com diferentes concentrações de conídios $\left(10^{3}, 10^{4}\right.$ e $10^{5}$ conídios $\left.\mathrm{mL}^{-1}\right)$ e tratados com água destilada ou quitosana a $10 \mathrm{~g} \mathrm{~L}^{-1}$ (Tabela 1), obteve-se, pela análise de variância, efeito significativo para o fator tratamento, para o fator concentração de inóculo e, também, para a interação entre os dois fatores. Em todas as concentrações de conídios testadas, a imersão em quitosana reduziu a severidade da doença, com efeito pronunciado nas maçãs infectadas com $10^{4}$ conídios $\mathrm{mL}^{-1}$. No caso das maçãs imersas em água destilada, aquelas infectadas com a menor concentração de conídios $\left(10^{3}\right.$ conídios $\left.\mathrm{mL}^{-1}\right)$ apresentaram menor severidade da doença (Tabela 1). O nível médio de

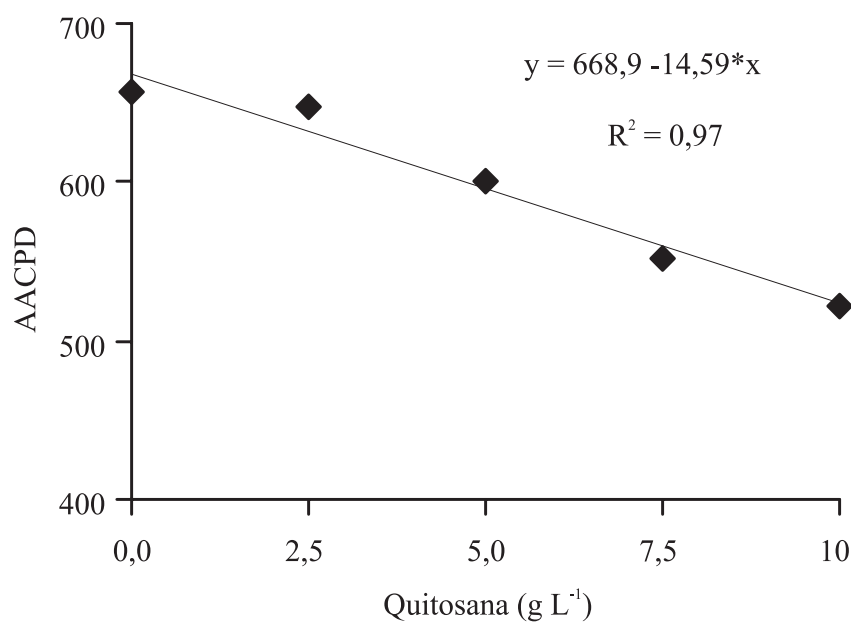

Figura 1. Efeito de doses de quitosana sobre a severidade da podridão-amarga (Colletotrichum acutatum) em frutos de maçã, representada pela área abaixo da curva de progresso da doença (AACPD). *Coeficiente de inclinação da reta significativo a $5 \%$ de probabilidade, pelo teste $\mathrm{t}$. controle da podridão-amarga, mediante a imersão em quitosana, foi de $20 \%$.

Os tratamentos com quitosana 10 e $20 \mathrm{~g} \mathrm{~L}^{-1}$ reduziram a severidade da doença nos frutos em relação à testemunha (frutos imersos em água destilada), em todos os pHs (Tabela 2). Houve efeito de doses e do $\mathrm{pH}$ da suspensão de quitosana sobre a severidade da doença, e a interação entre os dois fatores foi significativa. A dose de $20 \mathrm{~g} \mathrm{~L}^{-1}$ reduziu a severidade da doença nos pHs 2,4 e 4, em comparação à dose de $10 \mathrm{~g} \mathrm{~L}^{-1}$, porém, no $\mathrm{pH} 5,6$ as duas concentrações do polissacarídeo não diferiram entre si. A dose de $20 \mathrm{~g} \mathrm{~L}^{-1}$, combinada com o pH 4, reduziu em mais de $44 \%$ a severidade da podridão-amarga, contra $26 \%$ de controle obtido pela suspensão de quitosana a $10 \mathrm{~g} \mathrm{~L}^{-1}$ com o mesmo $\mathrm{pH}$ (Tabela 2). No entanto, o uso da quitosana a $20 \mathrm{~g} \mathrm{~L}^{-1}$ para o tratamento de frutos em larga escala apresenta algumas desvantagens operacionais, em virtude da elevada viscosidade dessa suspensão, além do maior gasto com o polissacarídeo.

Devlieguere et al. (2004) compararam diferentes doses de quitosana com $\mathrm{pH} 4$ ou 6 e obtiveram maior

Tabela 1. Efeito de quitosana aplicada 24 horas após a inoculação de Colletotrichum acutatum sobre a severidade da podridão-amarga em frutos de maçã representada pela área abaixo da curva de progresso da doença (AACPD) ${ }^{(1)}$.

\begin{tabular}{lccc}
\hline Tratamento & \multicolumn{3}{c}{ C. acutatum $\left(\right.$ conídios $\left.\mathrm{mL}^{-1}\right)$} \\
\cline { 2 - 4 } & $10^{3}$ & $10^{4}$ & $10^{5}$ \\
\hline Água & $493 \mathrm{bA}$ & $540 \mathrm{aA}$ & $551 \mathrm{aA}$ \\
Quitosana $\left(10 \mathrm{~g} \mathrm{~L}^{-1}\right)$ & $443 \mathrm{aB}$ & $408 \mathrm{bB}$ & $452 \mathrm{aB}$ \\
\hline
\end{tabular}

${ }^{(1)}$ Médias seguidas de letras iguais, minúsculas nas linhas e maiúsculas nas colunas, não diferem entre si pelo teste SNK, a 5\% de probabilidade.

Tabela 2. Efeito de doses e pH da suspensão de quitosana aplicada 24 horas após a inoculação de Colletotrichum acutatum, sobre a severidade da podridão-amarga em frutos de maçã, representada pela área abaixo da curva de progresso da doença (AACPD) ${ }^{(1)}$.

\begin{tabular}{|c|c|c|c|c|c|c|}
\hline \multirow[t]{3}{*}{ Tratamento } & \multicolumn{6}{|c|}{ pH da suspensão de quitosana } \\
\hline & \multicolumn{2}{|c|}{2,4} & \multicolumn{2}{|c|}{4,0} & \multicolumn{2}{|c|}{5,6} \\
\hline & AACPD & $\mathrm{NC}^{(2)}$ & AACPD & $\mathrm{NC}$ & AACPD & $\mathrm{NC}$ \\
\hline Test & $603 \mathrm{aA}$ & 0,0 & $603 \mathrm{aA}$ & 0,0 & $603 \mathrm{aA}$ & $\overline{0,0}$ \\
\hline Quitosana $\left(10 \mathrm{~g} \mathrm{~L}^{-1}\right)$ & $567 \mathrm{aB}$ & 5,9 & $444 \mathrm{bB}$ & 26,3 & $567 \mathrm{aB}$ & 5,9 \\
\hline Quitosana $\left(20 \mathrm{~g} \mathrm{~L}^{-1}\right)$ & $535 \mathrm{aC}$ & 11,2 & $333 \mathrm{bC}$ & 44,8 & $567 \mathrm{aB}$ & 5,9 \\
\hline
\end{tabular}

${ }^{(1)}$ Médias seguidas de letras iguais, minúsculas nas linhas e maiúsculas nas colunas, não diferem entre si pelo teste SNK, a 5\% de probabilidade.

${ }^{(2)} \mathrm{NC}$, nível de controle (\%) em relação à testemunha. 
efeito antimicrobiano sobre Candida lambica no $\mathrm{pH}$ inferior. $\mathrm{O}$ maior número de grupamentos amino, protonados nas cadeias do polissacarídeo em soluções mais ácidas, pode interagir mais intensamente com as cargas negativas presentes na membrana plasmática dos microrganismos, o que resulta em aumento na atividade antibiótica (Benhamou, 1992). Isso ajuda a explicar o maior controle de C. acutatum, no presente estudo, nos frutos de maçã imersos em pH 4 em relação ao $\mathrm{pH} 5,6$. Entretanto, as suspensões com pH 2,4 não foram eficientes em reduzir a severidade da doença. Outros pesquisadores obtiveram redução da severidade de podridão, em frutos como morango, cereja, uva e mamão com o uso de suspensões de quitosana com valores de $\mathrm{pH}$ entre 3,5 e 5,6 (El Ghaouth et al., 1992; Romanazzi et al., 2002, 2003; Cia, 2005; Camilli et al., 2007).

A incorporação da quitosana em meio de cultura afetou negativamente o crescimento micelial de C. acutatum, e a concentração de $4 \mathrm{~g} \mathrm{~L}^{-1}$ reduziu $\mathrm{o}$ diâmetro da colônia em cerca de 41\% (Figura 2). A antibiose in vitro por ação do polissacarídeo já foi demonstrada contra uma série de fungos fitopatogênicos, entre eles Botrytis cinerea, Penicillium expansum e Pythium aphanidermatum (El Ghaouth et al., 1992, 1994; Liu et al, 2007; Camilli et al., 2007).

Houve efeito quantitativo da quitosana sobre a germinação de conídios de $C$. acutatum. Todas as doses testadas diminuíram a emissão do tubo germinativo, e, na de $100 \mu \mathrm{g} \mathrm{mL}^{-1}$, a germinação de conídios foi $66 \%$ inferior ao controle (Figura 2). Nos tratamentos a partir de $50 \mu \mathrm{g} \mathrm{mL} \mathrm{m}^{-1}$, foram observadas alterações morfológicas no tubo germinativo, os quais se apresentaram mais espessos, atrofiados e com ramificação excessiva. Esses resultados corroboram diversos trabalhos ao mostrar a redução da germinação de conídios de fungos fitopatogênicos pelo emprego de quitosana. Porém a maioria dos autores desses trabalhos utilizou concentrações do polissacarídeo muito superiores às utilizadas no presente estudo, chegando a ser avaliada a dose de $5.000 \mu \mathrm{g} \mathrm{mL}^{-1}$ (El Ghaouth et al., 1992; Cia, 2005; Camilli et al., 2007). Com relação às alterações morfológicas em fungos, El Ghaouth et al. (1992) observaram que a quitosana provocou ramificações nas hifas de Rhizopus stolonifer. Liu et al. (2007) demonstraram que, além de reduzir a germinação de conídios de $P$. expansum e $B$. cinerea, a quitosana afetou a integridade da membrana plasmática de ambos os patógenos. Isso pode estar relacionado às interações da quitosana com cargas negativas de resíduos de macromoléculas, expostas na superfície das células fúngicas, que resultam em alterações na permeabilidade da membrana (Benhamou, 1992).
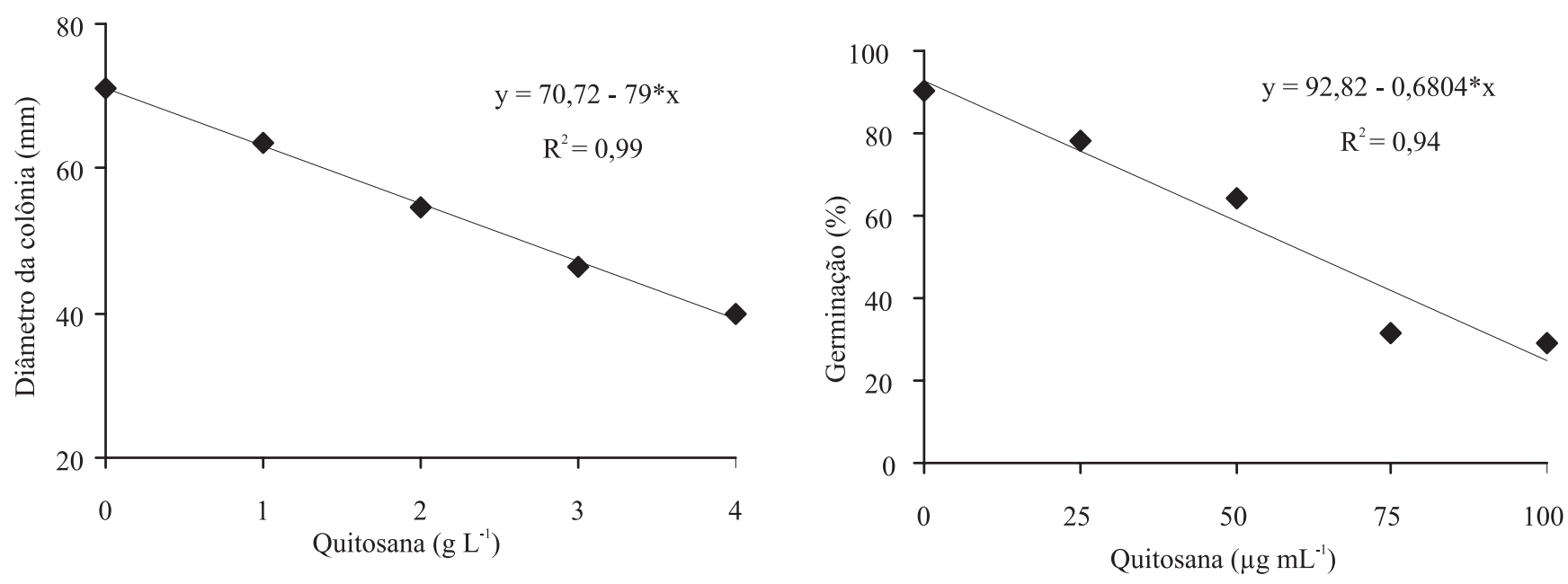

Figura 2. Efeito de doses de quitosana sobre o crescimento micelial em meio de cultura BDA (diâmetro da colônia) e sobre a germinação de conídios de Colletotrichum acutatum. *Coeficiente de inclinação da reta significativo, a 5\% de probabilidade, pelo teste $\mathrm{t}$. 
A atividade das enzimas peroxidases (densidade óptica a $470 \mathrm{~nm} \mathrm{mg}^{-1}$ de proteína por minuto) aumentou significativamente nos frutos feridos imersos em água $(12,4)$ e em quitosana $(12,5)$ que não foram infectados, em relação aos frutos infectados imersos em água $(8,6)$ e em quitosana $(8,1)$ e na testemunha $(9,4)$ imersa apenas em água. Não houve diferença na atividade de peroxidases nos frutos, no decorrer do tempo após a inoculação de $C$. acutatum ou ferimento, e não houve interação entre os fatores. Souza et al. (1999) estudaram a atividade de peroxidases em pêssegos feridos e obtiveram a elevação da atividade dessas enzimas. $\mathrm{O}$ aumento na atividade de peroxidases, associado aos ferimentos, é indicativo da oxidação de compostos fenólicos e da biossíntese de lignina, que atua como barreira à infecção microbiana. A reação ocorre em células vizinhas às infectadas ou feridas, as quais direcionam um sistema de defesa à área do ferimento (Campos et al., 2004).

Porém, frutos infectados com C. acutatum e também feridos durante a inoculação apresentaram a mesma atividade de peroxidases que a testemunha absoluta, representada por frutos apenas imersos em água. Assim, infere-se que as células de maçãs infectadas com $C$. acutatum não responderam, por meio dos seus mecanismos de defesa, à inoculação do patógeno. Nos tratamentos em que houve apenas ferimento, por não haver o patógeno, e a consequente morte do tecido ao redor do local onde foi inserida a agulha, as células vizinhas podem ter sido capazes de responder ao dano, o que resultou no aumento da atividade de peroxidases para o reparo do tecido lesionado. $\mathrm{O}$ tratamento das maçãs com quitosana, independentemente ou não da inoculação com C. acutatum, não alterou a atividade de peroxidases, em relação aos frutos somente imersos em água.

\section{Conclusões}

1. A suspensão de quitosana apresenta efeito antibiótico contra Colletotrichum acutatum, agente causal da podridão-amarga da macieira, e reduz a severidade da doença nos frutos imersos na suspensão.

2. A eficiência do produto é relacionada à concentração e ao $\mathrm{pH}$; a suspensão de quitosana a $10 \mathrm{~g} \mathrm{~L}^{-1}$ com pH 4 é a melhor combinação encontrada.

\section{Agradecimentos}

Ao Conselho Nacional de Desenvolvimento Científico e Tecnológico, pelo apoio financeiro; à empresa $\mathrm{AD}$ Oceanum Indústria e Comércio Ltda., pelo fornecimento de quitosana; e à Cooperserra, pela doação das maçãs.

\section{Referências}

ASSIS, O.B.G.; LEONI, A.M. Biofilmes comestíveis de quitosana: ação biofungicida sobre frutas fatiadas. Biotecnologia, Ciência e Desenvolvimento, v.30, p.33-38, 2003.

BAUTISTA-BAÑOS, S.; HERNANDEZ-LAUZARDO, A.N.; VELAZQUEZ-DEL VALLE, M.G.; HERNÁNDEZ-LÓPEZ, M.; BARKA, E.A.; BOSQUEZ-MOLINA, E.; WILSON, C.L. Chitosan as a potential natural compound to control pre and postharvest diseases of horticultural commodities. Crop Protection, v.25, p.108-118, 2006

BENHAMOU, N. Ultrastructural and cytochemical aspects of chitosan on Fusarium oxysporum f. sp. radicis-lycopersici, agent of tomato crown and root rot. Phytopathology, v.82, p.1185-1193, 1992.

BLEICHER, J. História da macieira. In: A Cultura da macieira. Florianópolis: EPAGRI, 2002. p.29-36.

BONETI, J.I.; KATSURAYAMA, Y.; BLEICHER, J. Doenças da macieira. In: A Cultura da macieira. Florianópolis: EPAGRI, 2002. p.527-555.

BRADFORD, M.M. A rapid and sensitive method for the quantitation of microgram quatities of protein utilizing the principle of protein-dye binding. Analytical Biochemistry, v.72, p.248-254, 1976.

CAMILli, E.C.; BENATO, E.A.; PASCHOLATI, S.F.; CIA, P. Avaliação de quitosana, aplicada em pós-colheita, na proteção de uva "Itália" contra Botrytis cinerea. Summa Phytopathologica, v.33, p.215-221, 2007.

CAMPOS, A.D.; FERREIRA, A.G.; HAMPE, M.M.V.; ANTUNES, I.F.; BRANCÃO, N.; SILVEIRA, E.P. da; OSÓRIO, V.A.; AUGUSTIN, E. Atividade de peroxidase e polifenoloxidase na resistência do feijão à antracnose. Pesquisa Agropecuária Brasileira, v.39, p.637-643, 2004.

CAVALCANTI, L.S.; DI PIERO, R.M.; PASCHOLATI, I.S.F.; RESENDE, M.L.V.; ROMERO, R. da S. Indução de resistência em plantas a patógenos e insetos. Piracicaba: FEALQ, 2005. 263p.

CIA, P. Avaliação de agentes bióticos e abióticos na indução de resistência e no controle pós-colheita de antracnose (Colletotrichum gloeosporioides) em mamão (Carica papaya). 2005. Tese (Doutorado) - Escola Superior de Agricultura Luiz de Queiroz, Piracicaba.

DE CAPDEVILlE, G.; WILSON, C.L.; BEER, S.V.; AIST, J.R. Alternative disease control agents induce resistance to blue mold in harvest 'Red Delicious' apple fruit. Phytopathology, v.92, p.900-908, 2002. 
DENARDI, F.; BERTON, O.; SPENGLER, M.M. Resistência genética à podridão-amarga em maçãs, determinada pela taxa de desenvolvimento da doença em frutos com e sem ferimentos. Revista Brasileira de Fruticultura, v.25, p.494-497, 2003.

DEVLIEGUERE, F.; VERMELEUN, A.; DEBEVERE, J. Chitosan: antimicrobial activity, interactions with food components and applicability as a coating on fruit and vegetables. Food Microbiology, v.21, p.703-714, 2004.

EL GHAOUTH, A.; ARUAL, J.; GRENIER, J.; ASSELIN, A. Antifungal activity of chitosan on two postharvest pathogens of strawberry fruits. Phytopatology, v.82, p.398-402, 1992.

EL GHAOUTH, A.; ARUL, J.; GRENIER, J.; BENHAMOU, N.; ASSELIN, A. Effect of chitosan on cucumber plants: suppression of Pythium aphanidermatum and induction of defence reactions. Phytopathology, v.84, p.313-320, 1994.

FERREIRA, D.F. Manual do sistema SISVAR para análises estatísticas. Disponível em: <http://www.dex.ufla.br/ danielff/ sisvarmanual.pdf $>$. Acesso em: 12 mar. 2009.

GOOSEN, M.F.A. Application of chitin and chitosan. Switzerland: Technomic Publishing AG, 1997. 336p.

HAMMERSCHMIDT, R.; NUCKLES, E.M.; KUC, J. Association of enhanced peroxidase activity with induced systemic resistance of cucumber to Colletotrichum lagenarium. Physiological Plant Pathology, v.20, p.73-82, 1982.
LIU, L.; TIAN, S.; MENG, X.G.; XU, Y. Effects of chitosan on control of postharvest diseases and physiological responses of tomato fruits. Postharvest Biology and Tecnology, v.44, p.300-306, 2007.

ROMANAZZI, G.; NIGRO, F.; IPPOLITO, A. Short hypobaric treatments potentiate the effect of chitosan in reducing storage decay of sweet cherries. Postharvest Biology and Technology, v.29, p.73-80, 2003.

ROMANAZZI, G.; NIGRO, E.; IPPOLITO, A.; DI VENERE, D.; SALERNO, M. Effects of pre- and postharvest chitosan treatments to control storage grey mold of Table grapes. Journal of Food Science, v.67, p.1862-1867, 2002.

SANTOS, J.E. dos; SOARES, J. da P.; DOCKAL, E.R.; CAMPANA FILHO, S.P.; CAVALHEIRO, É.T.G. Caracterização de quitosanas comerciais de diferentes origens. Polímeros: ciência e tecnologia, v.13, p.242-249, 2003.

SHANNER, G.; FINNEY, R.E. The effect of nitrogen fertilization on the expression of slow mildewing resistance in knox wheat. Phytopathology, v.67, p.1051-1056, 1977.

SOUZA, A.L.B. de; CHITARRA, M.I.F.; CHITARRA, A.B.; MACHADO, J. da C. Respostas bioquímicas em tecidos de pêssego ferido mecanicamente e tratado com $\mathrm{CaCl}_{2}$ no local da injúria. Ciência e Agrotecnologia, v.23, p.658-666, 1999.

Recebido em 27 de agosto de 2009 e aprovado em 14 de novembro de 2009 